\title{
National Conference on Advances in Material Science for Energy Applications
}

\author{
S. Anantha Ramakrishna, ${ }^{1}$ Ramesh Chandra, ${ }^{2}$ G. N. Tiwari, ${ }^{3}$ \\ P. Mandal, ${ }^{4}$ and R. K. Shivpuri ${ }^{5}$ \\ ${ }^{1}$ Department of Physics, Indian Institute of Technology Kanpur, Kanpur 208016, India \\ ${ }^{2}$ Institute Instrumentation Centre, Indian Institute of Technology Roorkee, Roorkee 247667, India \\ ${ }^{3}$ Centre for Energy Studies, Indian Institute of Technology Delhi, Delhi 110016, India \\ ${ }^{4}$ Department of Physics, University of Petroleum and Energy Studies, Dehradun 248007, India \\ ${ }^{5}$ Department of Nuclear Science and Technology, University of Petroleum and Energy Studies, Dehradun 248007, India
}

Correspondence should be addressed to S. Anantha Ramakrishna; sar@iitk.ac.in

Received 7 October 2014; Accepted 7 October 2014; Published 22 December 2014

Copyright (c) 2014 S. Anantha Ramakrishna et al. This is an open access article distributed under the Creative Commons Attribution License, which permits unrestricted use, distribution, and reproduction in any medium, provided the original work is properly cited.

Aims and Scope. The National Conference on "Advances in Material Science for Energy Applications" (AMSEA) was organized by University of Petroleum and Energy Studies, Dehradun, India, for the first time. The aim of the conference was to bring experts from all over the country to showcase their contributions towards the advances in the science of materials for energy applications. In addition, the conference intended to educate the people about the usefulness of solar energy and nuclear energy in filling the gigantic gap between the energy production and consumption. The conference was a good platform for young scientists, engineers, research scholars, and students to exchange their thoughts and ideas and to encourage further development of the existing knowledge on energy harvesting.

During the two-day conference (9-10 January 2014), several important topics related to fabrication and characterization of materials for energy applications such as "Materials/techniques for solar energy applications," "Advances in thin film technology," "Optically-active nano-structured materials," "Advances in nanofluids," "Advanced materials for nuclear energy applications," and "Advances in synthesis and characterization technique" were covered in lectures and poster sessions. The conference started with distinguished and plenary lectures delivered by leading experts in Material Science from reputed institutes like IITs and universities in the country. In addition, each individual session began with invited talks of well-known researchers in the respective fields. The conference was a great success, having a significant number of participants contributing their papers to the sessions.

The published proceeding papers cover topics on energy storage, solar cell, radiation detector, and materials for sensor applications, industrial lubricants, and so forth. Authors of these papers have shown the significance of the materials and methods or technology developed. For example, V. Nayak et al. have studied $\mathrm{BeH}_{2}$ as hydrogen storage material. $\mathrm{M}$. Tomar et al. have investigated various materials for $\mathrm{NO}_{2}$ and $\mathrm{SO}_{2}$ gas sensors. J. Aggarwal et al. have proposed a prototype device for solar harnessing. There is also a report on materials for semiconductor radiation detector by A. Garg et al. Other research groups have developed and characterized various materials having direct or indirect impact on energy applications.

\section{Acknowledgments}

The conference was well supported financially by the Department of Science and Technology (SERB division) of Government of India, Sinsil International, Aimil Ltd. (Instruments and Technologies), India, Allahabad Bank, India. We owe special thanks to Dr. Parag Diwan, Vice Chancellor, and Dr. Utpal Ghosh, Pro-Vice Chancellor of UPES, for their support and encouragement in conducting such conference of national importance. We thank Mr. Dinesh Agarwal, Hon'ble 
Cabinet Minister, Government of Uttarakhand, India, for inaugurating the conference.

S. Anantha Ramakrishna Ramesh Chandra G. N. Tiwari P. Mandal R. K. Shivpuri 

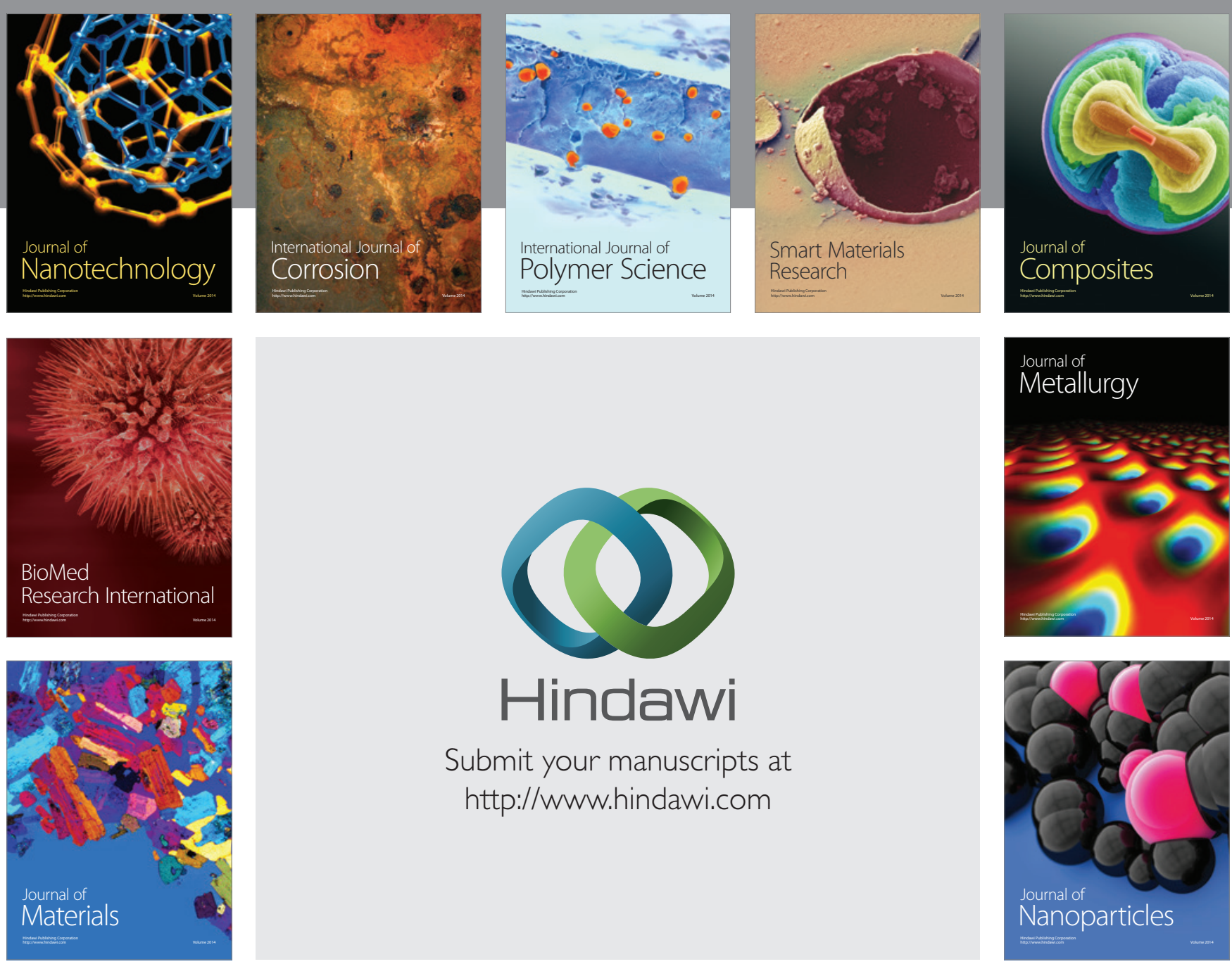

Submit your manuscripts at http://www.hindawi.com
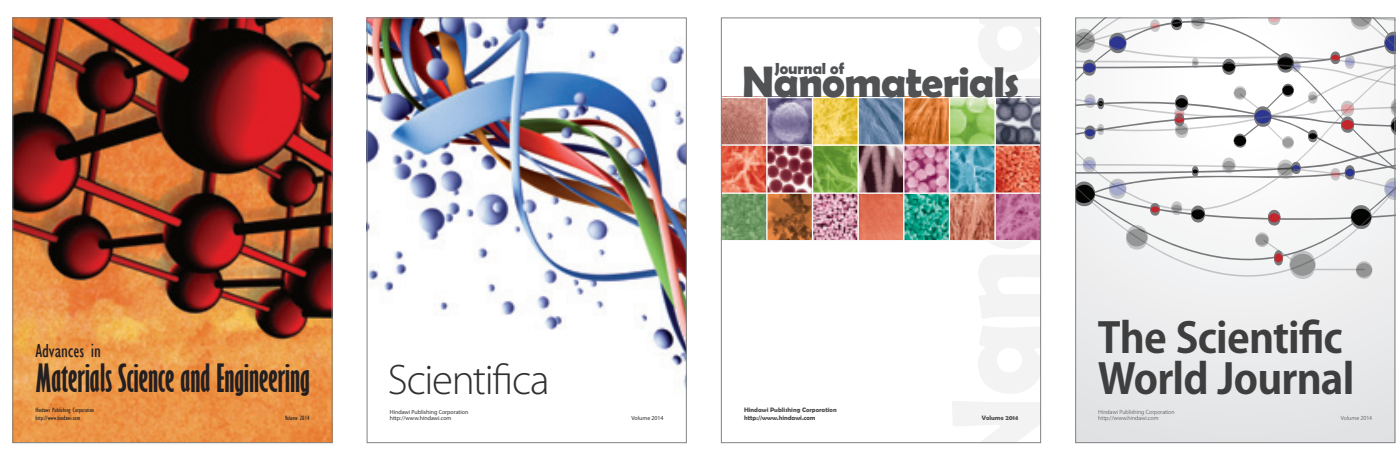

\section{The Scientific World Journal}
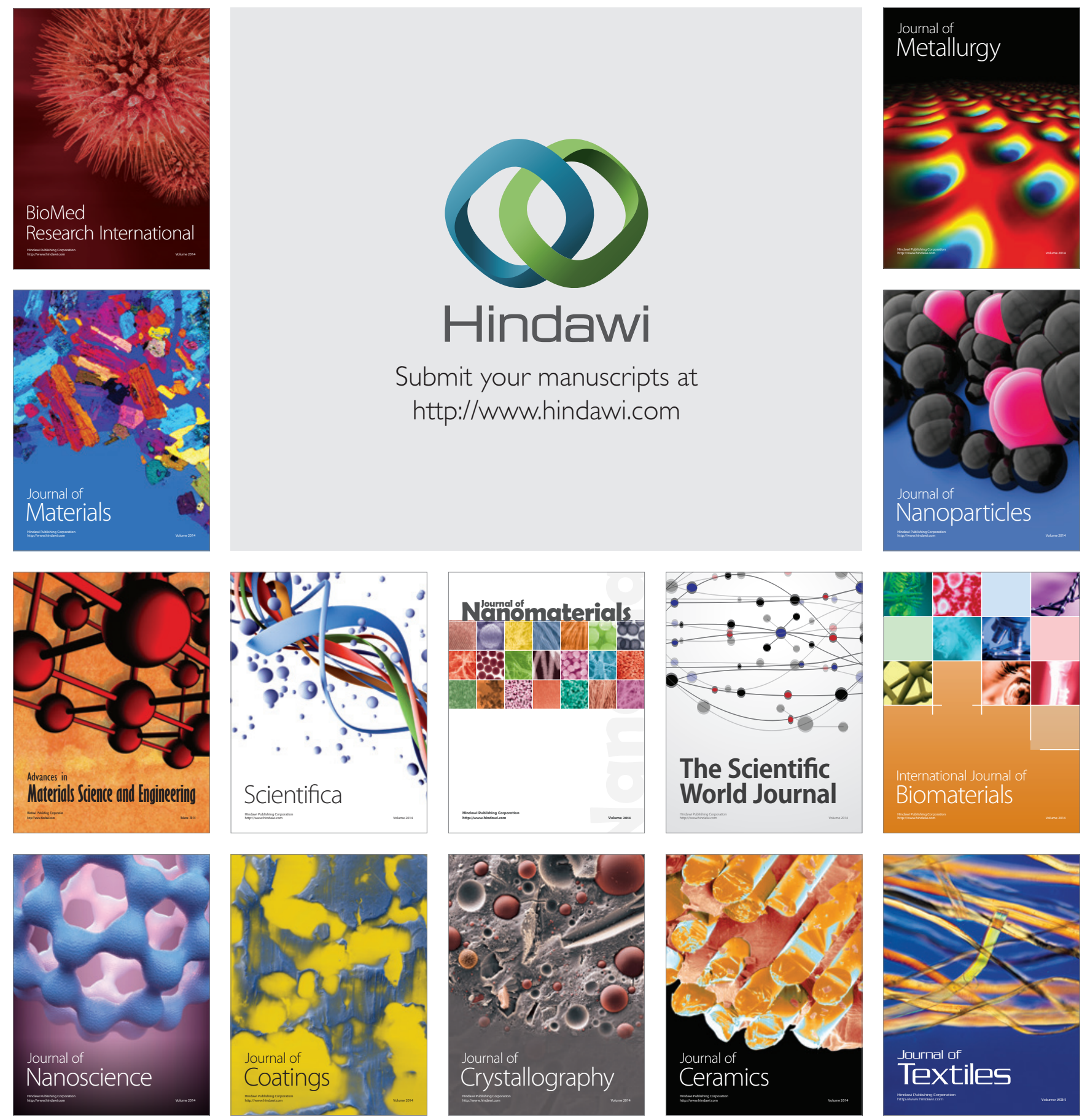